\title{
An Operation Control Strategy for the Connected Maglev Trains Based on Vehicle-Borne Battery Condition Monitoring
}

\author{
Wenjing Zhang $(\mathbb{D}$, Wenjun Wei, Yifan Yang, and Nan Nan \\ School of Electronic and Information Engineering, Beijing Jiaotong University, Beijing 100044, China \\ Correspondence should be addressed to Wenjing Zhang; zhangwj@bjtu.edu.cn
}

Received 8 December 2017; Accepted 7 March 2018; Published 12 April 2018

Academic Editor: Cesar Briso-Rodriguez

Copyright (c) 2018 Wenjing Zhang et al. This is an open access article distributed under the Creative Commons Attribution License, which permits unrestricted use, distribution, and reproduction in any medium, provided the original work is properly cited.

\begin{abstract}
Vehicle-borne battery condition is an important factor affecting the efficiency of the maglev train operation and other connected ones. To effectively eliminate the influence of the battery condition and improve the operation efficiency of the connected maglev trains, an operation control strategy is proposed to guarantee train operation safety. First, based on Internet of Things, a sensor network is designed to monitor vehicle-borne battery condition in each vehicle of the train. Second, the train Operation Control System collects battery data of all vehicles in a maglev train by Train Communication Network. Third, all connected maglev trains share the battery data via a $38 \mathrm{GHz}$ directional Radio Communication System and adjust operation control strategy accordingly. Simulation results indicate that the proposed strategy can guarantee the operation safety of the connected maglev trains.
\end{abstract}

\section{Introduction}

After the introduction of high-speed maglev train Transrapid-08 into Shanghai in 2002 and with the operations of both Airport Line of Changsha in 2016 and S1 Line of Beijing in 2017, maglev transportation system has received more and more attention in China $[1,2]$. Compared with the conventional wheel-rail transportation systems, the maglev transportation system has many excellent features such as low environmental noise, small turning radius, high climbing slope ability, strong weather resistance, low maintenance cost, and long life-span [3].

Normally, based on five speed curve limits including the minimum speed-up limit, the minimum levitation limit, the maximum safety braking limit, the maximum speed running limit, and the maximum speed limit, the train Operation Control System (OCS), which has four subsystems including Central Control System (CCS), Decentralization Control System (DCS), Vehicle Control System (VCS), and $38 \mathrm{GHz}$ directional Radio Communication System (RCS), formulates an operation control strategy real-timely to guarantee train operation safety [4].

However, for construction cost consideration, only station decentralizations and Auxiliary Stopping Area (ASA) of section decentralizations are equipped with Power Rail (PR), making it discontinuous. In case of emergency, VCS requests DCS to shut off the Propulsion Power-Supply System (PPS) and then the train-borne batteries are the only energy source for all train-borne electrical equipment to keep the train running to the next ASA. Unfortunately, the train cannot run again after it stops in the track without PR [5].

In the routine operation, the running speed is around $200 \mathrm{~km} / \mathrm{h}$ for the medium-speed train and about $400 \mathrm{~km} / \mathrm{h}$ for the high-speed train; the Vehicle Electrical Grid (VEG) is supplied by the vehicle-borne linear generator because of high power-generating efficiency at high speed. However, when the train speed decreases to $100 \mathrm{~km} / \mathrm{h}$ or lower, the power-generating capacity of the linear generator drops too much to supply enough power to VEG. In this case, the trainborne batteries provide supplementary energy to VEG. For safety, during pull-in and departure station, the train speed is relatively low (lower than $100 \mathrm{~km} / \mathrm{h}$ ); VEG has to depend on the train-borne batteries. Hence, the battery conditions, especially the remaining capacity, are crucial to the train operation safety.

When the maglev train stops in the station or ASA in the section decentralization, vehicle-borne collectors will charge batteries through PR and the vehicle-borne batteries are in the high current mode, resulting in performance degradation easily. Therefore, it is of great significance to monitor the 
battery condition to prolong the battery life $[6,7]$ and adjust the operation strategy dynamically. Moreover, during the following operation for the connected trains, the following train has to adjust the operation control strategy in real-time according to both its self-condition and that of the leading one to prevent it from crashing.

In these years, with the rapid development of wireless communication and network technique, a wide range of Internet of Things (IoT) applications has been found in many areas such as smart cities [8], spatial crowdsourcing [9], and crowd dynamics management [10]. IoT is expected to achieve intelligent information processing, pervasive sensing, and efficient resource management in sensor network [11-14].

The Train Communication Network (TCN) standard was approved by the International Electrotechnical Commission (IEC) and the IEEE in 1999 to warrant interoperability of train and equipment. TCN encompasses two serial masterslave buses: the Wire Train Bus (WTB) and the Multifunction Vehicle Bus (MVB). Nowadays, TCN is widely used in highspeed rail trains and metro trains [15-19].

Recently, several fault detection methods have been presented to enhance the safety of the maglev train. A Bayesian network based detection method has been conducted [20,21] to investigate acceleration sensor failures and analyse the multistate of the braking system. For maglev train, a risk modelling method of the failure event tree is given to detect the failure of levitation control system in [22].

In this paper, using IoT, a sensor network architecture is designed to monitor the vehicle-borne battery condition data in each vehicle; all these data in the train are collected by OCS through TCN and connected trains share them via RCS. Further, a new operation control strategy is proposed to guarantee the safety of the following operation for the connected maglev trains.

The main contributions of this paper are as follows.

(1) For existing operation control strategies, it is assumed that the train-borne batteries have full capacity all the time. The proposed operation control strategy regards the battery conditions as variable states and formulates strategy in realtime according to the conditions of the batteries.

(2) Comparing with existing operation control strategies, the proposed strategy takes other connected trains into consideration and adjusts the operation control strategy dynamically.

The rest of this paper is organized as follows. In Section 2, we analyse main resistance and energy consumption of the maglev train briefly. Section 3 is dedicated to designing a sensor network for the connected maglev trains to monitor battery conditions and exchange related information. In Section 4, based on battery condition data, an operation control strategy is proposed to guarantee the train safety in both station and section decentralizations. Section 5 is devoted to the simulation evaluation of the proposed scheme. Finally, conclusions are presented in Section 6.

\section{Dynamic Analysis of the Maglev Train}

Generally, the maglev train can be regarded as a rigid body when we study the operation control strategy. The total resistance $f_{\text {sum }}$ mainly comes from the air, rail line, magnetic force, eddy current braking force, and other additional forces. The total resistance $f_{\text {sum }}$ (unit is $\mathrm{KN}$, the same below) can be described as

$$
f_{\text {sum }}=f_{\text {air }}+f_{\text {mag }}+f_{\text {eddy }}+f_{\text {motor }}+f_{\text {skid }}+f_{i}+f_{r},
$$

where $f_{\text {air }}$ is the air resistance, $f_{\mathrm{mag}}$ is the magnetic resistance, $f_{\text {eddy }}$ is the eddy current braking resistance, $f_{\text {motor }}$ is the linear motor braking resistance, $f_{\text {skid }}$ is the gliding skid braking resistance, $f_{i}$ is the curve resistance, and $f_{r}$ is the gradient resistance.

The intrinsic resistance includes air resistance and intrinsic magnetic resistance [11]. Without considering the wind condition, the air resistance and magnetic resistance are given by

$$
\begin{aligned}
f_{\text {air }} & =2.8 \times 10^{-3} \times(0.265 N+0.3) v^{2}, \\
f_{\text {mag }} & =1.86 N\left(1-e^{-v / 108}\right),
\end{aligned}
$$

where $N$ is the number of train vehicles and $v$ is the train speed.

For the maglev train, the braking force is mainly from the reverse braking, the resistance braking, the eddy current braking, the wearing plate braking, and the gliding skid braking.

Normally, the linear motor makes maglev train slow down by reverse braking and energy consume braking. The braking force $f_{\text {motor }}$ is given as

$$
\begin{aligned}
& f_{\text {motor }} \\
& \quad= \begin{cases}0, & (v<10 \mathrm{~km} / \mathrm{h}) \\
2.03 N, & (10 \mathrm{~km} / \mathrm{h}<v<70 \mathrm{~km} / \mathrm{h}) \\
N\left(\frac{146}{v}-0.2\right), & (v>70 \mathrm{~km} / \mathrm{h}) .\end{cases}
\end{aligned}
$$

In case of emergency, VSC sends blocking propulsion power request to DCS to shut off PPS and the eddy current braking is initiated. The force of the eddy current braking is as follows:

$$
f_{\text {eddy }}=f_{\text {eddy }-x}+f_{\text {plate }},
$$

where $f_{\text {eddy }-x}$ is the eddy current braking resistance in running direction and can be described as follows:

$$
f_{\text {eddy } x}= \begin{cases}2.28 q N\left(0.014 I^{2}+0.004 I\right) \cdot\left(1-0.6 e^{-v / 30}\right) & (10 \mathrm{~km} / \mathrm{h}<v<150 \mathrm{~km} / \mathrm{h}) \\ 0.032 q N I^{2} & (v>150 \mathrm{~km} / \mathrm{h}) .\end{cases}
$$


When the speed decreases to $130 \mathrm{~km} / \mathrm{h}$ or lower, the wearing plate braking is initiated to make attractive force between the eddy current electromagnet and the side rail of the line increase gradually; $f_{\text {plate }}$ is described as

$$
f_{\text {plate }}=N\left(0.0027 v^{2}-0.92 v+74\right) .
$$

Once the speed of the maglev train decreases to $10 \mathrm{~km} / \mathrm{h}$ or lower, the gliding skid braking is initiated to make the train stop.

$$
f_{\text {skid }}=\mu_{\text {skid }} N m g\left(1-\frac{i}{1000}\right),
$$

where $i$ is the gradient per millage, $m$ is train weight, $g$ is gravitational acceleration, and $\mu_{\text {skid }}$ is friction coefficient of the gliding skid braking and is given by

$$
\mu_{\text {skid }}=\left(0.123 \times 10^{-5} v^{2}-0.0025 v+0.2642\right) .
$$

Moreover, the gradient line forms an additional resistance to the train. The additional gradient resistance $f_{i}$ is

$$
f_{i}=\frac{i N m g}{1000} .
$$

In addition to the above-mentioned resistances, the curve line adds another additional curve resistance that can be described as follows:

$$
f_{r}=\frac{600 N m g}{R} .
$$

The train-borne equipment energy $E$ is

$$
E=E_{\text {lev }}+E_{\text {brake }}+E_{\text {equip }}
$$

where $E_{\text {lev }}$ is levitation energy, $E_{\text {brake }}$ is emergency braking energy, and $E_{\text {equip }}$ is vehicle-borne equipment consumption energy.

The train levitation power is

$$
P_{\text {lev }}=0.1049 v+1.006 m \text {. }
$$

Although the whole deceleration process of the train is variable, the deceleration in a short differential time within $\Delta t=:\left[t_{i}, t_{i+1}\right]$ can be assumed to remain constant. During $\left[t_{i}, t_{i+1}\right]$, the deceleration is $a\left(v_{i}\right)$. Therefore, the running distance $S$ can be obtained by

$$
\begin{aligned}
& v_{i+1}=v_{i}+a\left(v_{i}\right) \Delta t, \\
& S_{i+1}=S_{i}+a\left(v_{i}\right) \Delta t+0.5 a\left(v_{i}\right)(\Delta t)^{2} .
\end{aligned}
$$

\section{Vehicle-Borne Battery Condition Sensor Network for Connected Maglev Trains}

In this section, the impact of battery conditions on the operation and the monitored battery parameters are analyzed briefly. To share battery conditions for the connected maglev trains, a sensor network and a data exchange method are designed in detail.

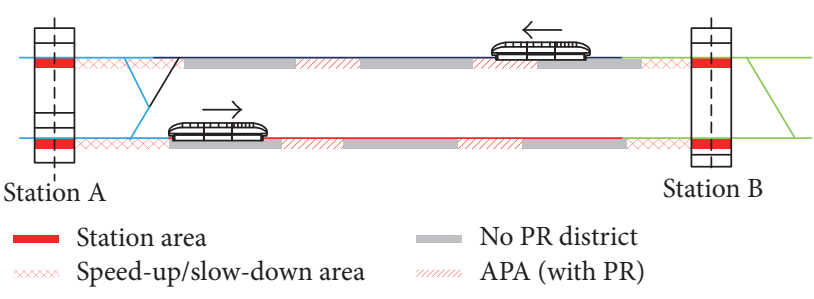

FIGURE 1: The sketch of a typical maglev transportation line.

3.1. The Impact of Battery Conditions on Maglev Train Operation. The line for the maglev train is divided into four types including station, speed-up area, track with ASA and PR, and track without PR, as shown in Figure 1.

As is shown in Figure 2(a), the train speed is usually lower than $100 \mathrm{~km} / \mathrm{h}$ in the station and vehicle-borne collectors provide the energy from PR for levitation and vehicle equipment including batteries and other electrical loads. When departing the station, with the power from PR, the train accelerates quickly to exceed the minimum levitation limit. In case of emergency, the train has to be braked to stop within either station or speed-up area. In this case, two possibilities should be evaluated by OCS: (1) if the train can still stop within the speed-up area, an emergency braking should be initiated; (2) if the train can only stop beyond the speed-up area, current operation strategy is kept for certain time and then train is braked to run to the next ASA in the section decentralization.

During section decentralization operation, when train speed is higher than $100 \mathrm{~km} / \mathrm{h}$, the vehicle-borne linear generators supply the levitation energy, as shown in Figure 2(b). However, when its speed is lower than $100 \mathrm{~km} / \mathrm{h}$, the vehicleborne batteries provide the levitation energy because vehicleborne linear generators cannot supply enough energy, as shown in Figure 2(c). Moreover, a stop-point-stepping method is employed to make the train run through ASA until forwarding to next station according to the arranged speed curves. In case of emergency, similar to the situation in the station, two possibilities should be considered: (1) if the train has to stop immediately because of some unexpected emergencies like a maintenance vehicle ahead, the train has to brake with the maximum deceleration; (2) otherwise, the running state and the deceleration process should be adjusted accordingly to make train stop in the next ASA.

3.2. Vehicle-Borne Battery Condition Monitoring. The normal working ranges of lithium batteries in the maglev train are shown in Table 1.

(1) Battery Temperature Monitoring. When discharging rate is too high, battery temperature increases quickly and forms hot air to rise in the tank. Therefore, the temperature sensors should be placed on the upper part of the box to obtain the actual temperature information easily. Using MicaZ modules of MEMSIC Inc., the temperature values and their corresponding conditions are described in Table 2.

(2) Battery Remaining Capacity Monitoring. The voltage and current of the battery are obtained from Vehicle Diagnosis 


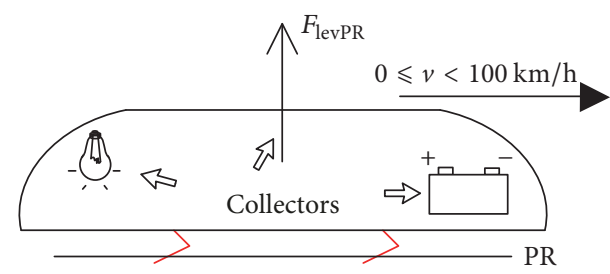

(a) Energy supplied by collectors

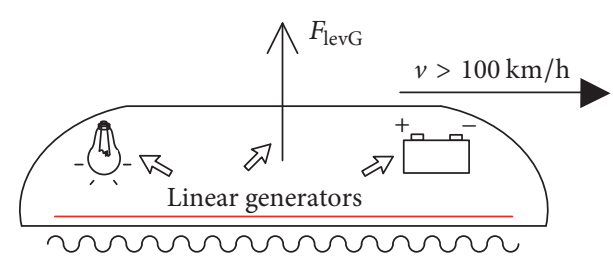

(b) Energy supplied by linear generator

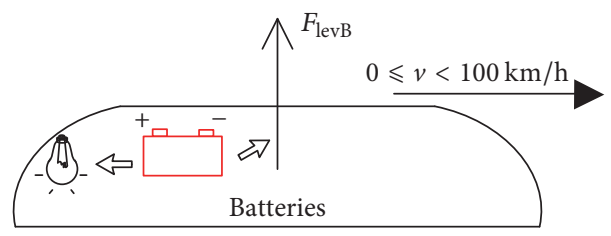

(c) Energy supplied by vehicle-borne batteries

FIGURE 2: Power supply modes for the maglev train.

TABLE 1: Lithium battery operating characteristics.

\begin{tabular}{lc}
\hline Parameters & Normal working range \\
\hline Temperature & $-20^{\circ} \mathrm{C}$ to $+55^{\circ} \mathrm{C}$ \\
Voltage & DC $440 \mathrm{~V}( \pm 20 \mathrm{~V})$ \\
Current & DC $0 \mathrm{~A}-40 \mathrm{~A}$ \\
\hline
\end{tabular}

TABLE 2: Temperature values and corresponding conditions.

\begin{tabular}{lc}
\hline Temperature values & Condition \\
\hline Lower than $-20^{\circ} \mathrm{C}$ & Too low \\
$-20^{\circ} \mathrm{C}$ to $55^{\circ} \mathrm{C}$ & Normal \\
Higher than $55^{\circ} \mathrm{C}$ & Too high \\
\hline
\end{tabular}

Computer (VDC), and the remaining capacity of the battery can be evaluated to realize the real-time monitoring of remaining capacity. The relationships between remaining capacity and corresponding conditions are shown in Table 3.

(3) Battery Visible Flame Monitoring. In the practical operation, the battery temperature often exceeds the normal limits. Unfortunately, VDC cannot tell whether there is fire or not. The flame sensors can be used to detect the visible battery flame. The relationships between the visible flame and corresponding conditions are shown in Table 4.

3.3. Vehicle-Borne Battery Sensor Network. The parameters indicating the conditions of the vehicle-borne battery include temperature, voltage, and current [23-26]. During the train operation, in order to prevent the batteries from overheating, their temperature ought to maintain a safe range. Meantime, voltage and current of each battery should keep at an appropriate level to guarantee the remaining energy for vehicleborne equipment and train levitation. When a maglev train stops in the station or ASA, its batteries must be checked to remain enough energy to provide its levitation to the next ASA and can perform an emergency braking before its departure.

Each vehicle of the maglev train has eight batteries including four $440 \mathrm{~V}$ and four $24 \mathrm{~V}$. Except for emergency-lighting depending on $24 \mathrm{~V}$ batteries, almost all train-borne systems including levitation and direction, braking, air-conditioning, and other ones are supplied by four $440 \mathrm{~V}$ batteries. Here, we only take four $440 \mathrm{~V}$ batteries into consideration. For a typical maglev train with six vehicles, a sensor network based on IoT to monitor vehicle-borne battery condition is shown in Figure 3. The network includes two Vehicle Safety Computers (VSCs) and two Mobile Radio Control Units (MRCUs) for two terminal vehicles and one Data Acquisition Unit (DAU) for each vehicle. In a vehicle, DAU gathers batteries condition data and sends them to VSCs; the master VSC formulates the operation control strategy accordingly (the master VSC is active and the slave one is in hot standby state).

Both head and tail vehicles have 2 directional antennas on top of them to form redundancy communication channels. Connected maglev trains exchange condition data via existing RCS, whose base stations are located along the rail line, as shown in Figure 4.

\section{Operation Control Strategy for the Connected Maglev Trains}

Considering the train-borne battery conditions, an operation control strategy for the independent maglev train is given in this section. Further, for the connected trains, based on five speed limits as shown in Figure 5, an operation control strategy for the following operation of the connected trains is discussed in detail.

Curve (1) is a minimum speed-up limit used to reach minimum speed, curve (2) is a minimum levitation limit considering running resistance and slope influence, curve (3) is a maximum safety-brake limit considering safe braking characteristics and slope influence, curve (4) is a maximum speed running limit, curve (5) is a maximum speed limit considering the train structure and all line conditions, and curve (6) is actual running speed limit. 
TABLE 3: Remaining capacity and corresponding condition.

Remaining capacity

Condition

Not enough to provide energy for levitation and emergency braking

Battery exhausted

Enough to provide energy for levitation and emergency braking, but cannot provide extra energy

for vehicle-borne equipment

No enough energy

Meets all the vehicle energy requirements

Sufficient electricity

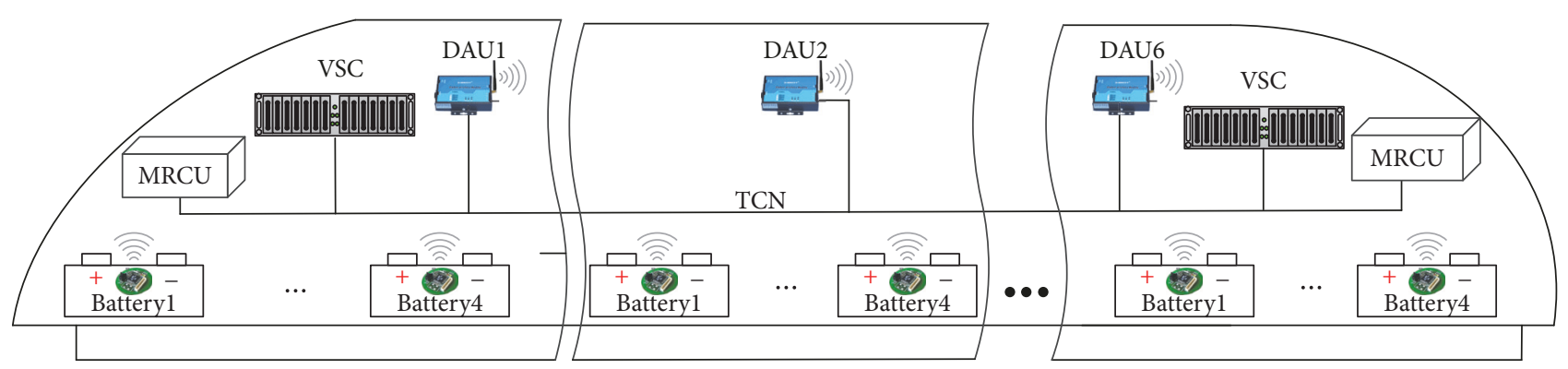

Figure 3: An IoT based sensor network scheme for the maglev train.

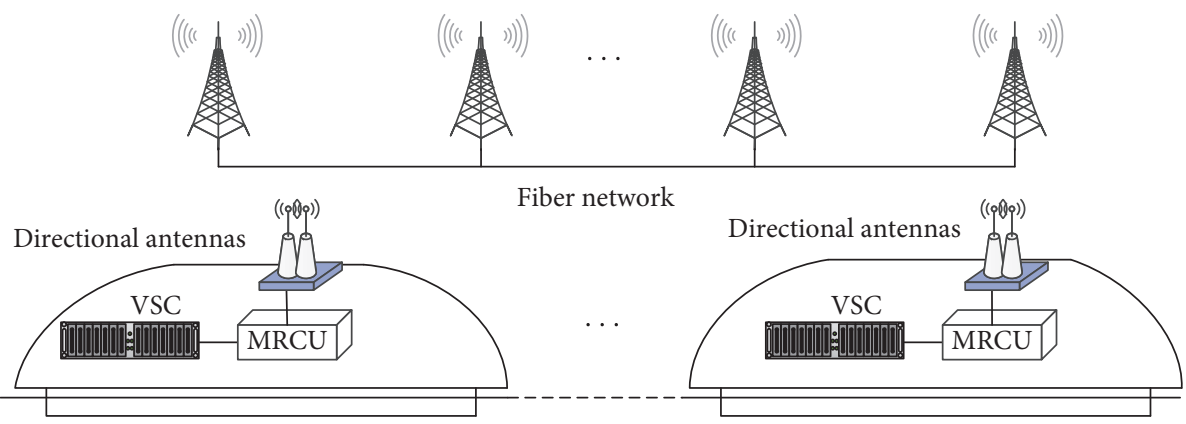

FIgURE 4: Data exchange scheme for connected maglev trains.

TABLE 4: Visible flame and corresponding condition.

\begin{tabular}{lc}
\hline Visible flame & Condition \\
\hline Yes & On fire \\
No & No fire \\
\hline
\end{tabular}

4.1. Battery Conditions Based Operation Strategy. Based on the battery parameters including temperature, voltage, current, and visible flame, different operation control strategies are employed to ensure the train operation safety. The battery remaining capacity can be calculated with battery voltage and current [23]. The battery parameters and corresponding operation control strategies are shown in Tables 5-7.

4.2. Operation Control Strategy for Departure and Pull-In. When the train departs from the station, the energy for levitation and vehicle-borne equipment is supplied by the collectors that are connected to PR. In order to run to the next ASA, all the vehicle-borne batteries have to be evaluated. The operation control strategy is to satisfy the minimum capacity requirement for levitation and emergency braking (at least once). Once the train speed is lower than the minimum

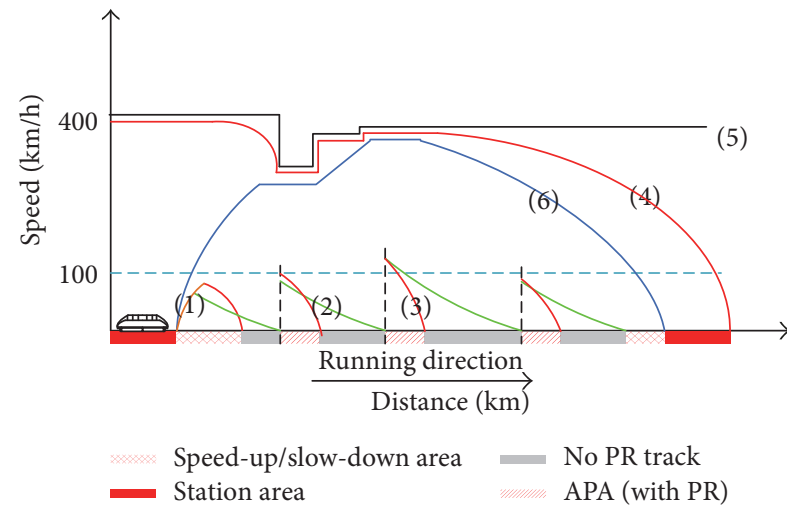

Figure 5: Speed limits for the maglev train.

levitation limit, PPS will be shut off, making the train float to the nearest ASA in levitation state.

In the pull-in deceleration area, the operation control strategy is to use kinetic and potential energy to run into the station, as shown in Figure 6. During approaching the station, if the initial speed $v_{1}>100 \mathrm{~km} / \mathrm{h}$, the gliding distance $S_{v 1}$ and the operation mode switching point (see point A: from 
TABLE 5: The temperature related strategies.

\begin{tabular}{ll}
\hline Temperature & Operation control strategies \\
\hline Lower than $-20^{\circ} \mathrm{C}$ & Pump hot air into the battery box \\
\hline$-20^{\circ} \mathrm{C}$ to $55^{\circ} \mathrm{C}$ & Run normally \\
\hline & $\begin{array}{l}\text { (1) VDC sends the high-temperature alarm to OCS to increase the cooling fan. } \\
\text { (2) VDC sends battery failure to OCS when the alarm keeps for over } 3 \text { minutes. } \\
\text { (3) If the temperature continues to rise but does not reach the limit of combustion, all passengers get off } \\
\text { after the train stops. } \\
\text { (4) If the temperature reaches the limit of combustion, VDC releases fire alarm, the train stops in the } \\
\text { nearest ASA. }\end{array}$ \\
\hline
\end{tabular}

TABLE 6: The remaining capacity related strategies.

\begin{tabular}{lc}
\hline Remaining capacity & \multicolumn{1}{c}{ Operation control strategies } \\
\hline $\begin{array}{l}\text { Not enough to provide energy for levitation and emergency } \\
\text { braking }\end{array}$ & $\begin{array}{c}\text { Turn off air conditioners and other vehicle-borne equipment. } \\
\text { The train is not allowed to run unless the required capacity is } \\
\text { charged. }\end{array}$
\end{tabular}

Enough to provide energy for levitation and emergency

braking, but cannot provide enough energy for vehicle-borne equipment

Meets all the vehicle energy requirements

TABLE 7: The visible flame related strategies.

\begin{tabular}{lc}
\hline Visible flame & Operation control strategies \\
\hline Yes & Perform an emergency braking \\
No & Run normally \\
\hline
\end{tabular}

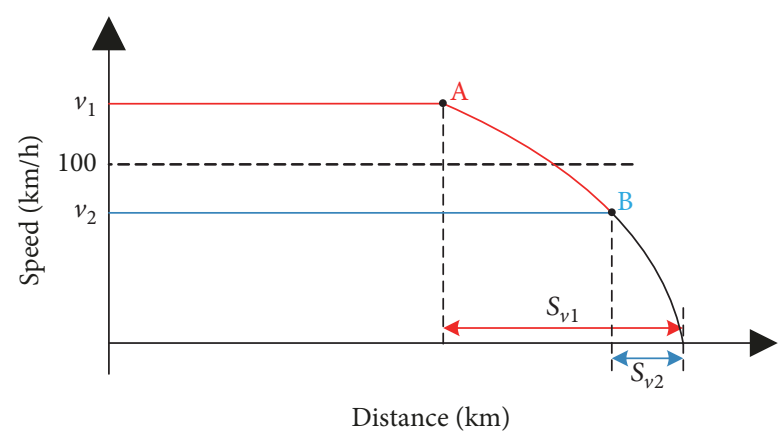

FIGURE 6: The lowest power consumption in the pull-in.

constant speed coasting mode to braking deceleration mode) are determined firstly according to (1)-(8) and (13), making the batteries supplied energy minimum in the distance $S_{v 1}$. On the other hand, when the initial speed $v_{2}<100 \mathrm{~km} / \mathrm{h}$, the energy for levitation and other equipment is supplied by the train-borne batteries; the gliding distance with kinetic and potential energy is only $S_{v 2}$ from the switching point B obtained in the same way of switching point A. In such case, the operation control strategy is to cut off the power for other train-borne equipment to guarantee the energy supply for levitation and emergency braking.

4.3. Section Operation Control Strategy for the Connected Trains. When connected trains run with the same direction
Turn off the vehicle-borne equipment to keep safe levitation to the next ASA for recharging. 


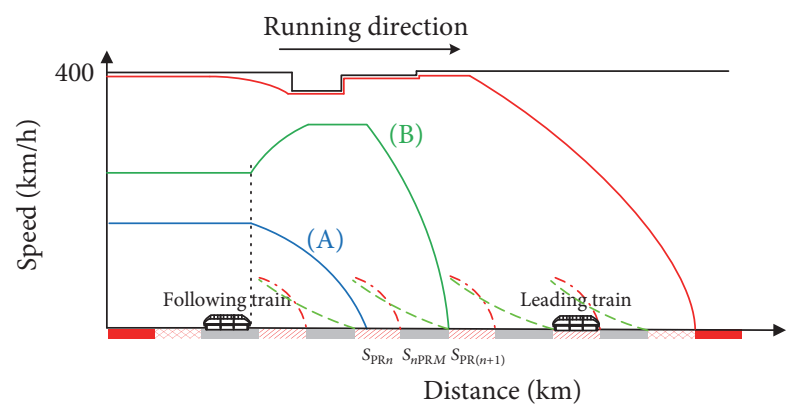

Figure 8: The operation control strategy for following train.

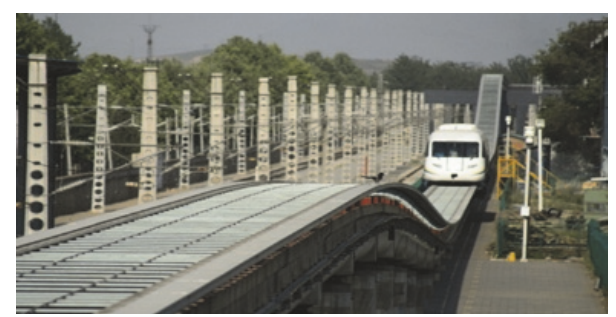

Figure 9: Map of the scenario for the experiment.

of the following train: (1) if the following interval is long enough and the following train cannot stop in the next ASA because of high speed, the following train can accelerate to the maximum speed, coast for a specific distance, and then brake to stop in the ASA that is behind the leading train (see curve (B)); (2) if the current speed is relatively low, the following train is braked to stop in the next ASA (see curve (A)).

\section{Simulation and Experimental Results}

In this section, a simulation is carried out and an experiment is performed to verify the effectiveness of the proposed operation control strategy and illustrate the applicability of the obtained results. The map of the scenario and the line sketch are shown in Figures 9 and 10; the parameters of the maglev train and the line are described Table 8.

The resistance and corresponding deceleration of the train at different speeds are shown in Figure 11. It can be seen that total deceleration is higher than $1 \mathrm{~m} / \mathrm{s}^{2}$. When the train speed is lower than $10 \mathrm{~km} / \mathrm{h}$, the deceleration is mainly from the gliding skid. When $10 \mathrm{~km} / \mathrm{h}<v<140 \mathrm{~km} / \mathrm{h}$, the eddy current braking provides the main resistance for the train. However, the air resistance and the eddy current braking supply the resistance for the train when $v>140 \mathrm{~km} / \mathrm{h}$.

The remaining capacity of the vehicle-borne battery is a key factor that affects the operation control strategy formulating. The speed-distance and energy-distance curves under the emergency braking and intrinsic resistance braking are shown in Figures 12 and 13. From Figure 12, the minimum running point and the related energy for levitation and other vehicle-borne equipment can be obtained. When the initial speed is $400 \mathrm{~km} / \mathrm{h}$, the braking distance is $2.65 \mathrm{~km}$ and the minimum battery capacity for levitation and other train equipment is $4.38 \mathrm{kWh}$. Meanwhile, the maximum running
TABLE 8: Parameters of the experimental line.

\begin{tabular}{lc}
\hline Parameters & $\begin{array}{c}\text { Numerical } \\
\text { value }\end{array}$ \\
\hline Total weight of single full load vehicle, $m(\mathrm{t})$ & 62 (terminal) \\
& 64.5 (middle) \\
27 (terminal) & 24.5 (middle) \\
Length of single vehicle, $L_{\mathrm{veh}}(\mathrm{m})$ & 6 \\
Number of vehicles, $N$ & 382 \\
Total train weight, $m_{T}(\mathrm{t})$ & 153 \\
Total train length, $L_{\text {trn }}(\mathrm{m})$ & 400 \\
Maximum speed, $v_{\text {max }}(\mathrm{km} / \mathrm{h})$ & 70.4 \\
Total capacity of four sets of batteries per & 109 \\
vehicle, $E_{\mathrm{btry}}(\mathrm{kwh})$ & 105 \\
Braking power $P_{b}(\mathrm{~kW})$ & 0.9 \\
Vehicle equipment power, $P_{e}(\mathrm{~kW})$ & 0.8 \\
Average propulsion acceleration, $a_{\mathrm{ac}}\left(\mathrm{m} / \mathrm{s}^{2}\right)$ & 210 \\
Average propulsion deceleration, $a_{\mathrm{dc}}\left(\mathrm{m} / \mathrm{s}^{2}\right)$ & 2648 \\
Platform length, $L_{\text {stn }}(\mathrm{m})$ & 1718 \\
Shortest length of departure $\mathrm{PR}, S_{\mathrm{dprt}}(\mathrm{m})$ & 551 \\
Shortest length of pull-in PR, $S_{\mathrm{pi}}(\mathrm{m})$ & 455 \\
The length of the first departure track without & 6025 \\
PR, $S_{n \mathrm{PR} 1}(\mathrm{~m})$ & \\
The length of first approaching track without & \\
PR, $S_{n \mathrm{PR} z}(\mathrm{~m})$ & \\
The length of the longest track without PR in & \\
the section decentralization, $S_{n \mathrm{PR} M}(\mathrm{~m})$ & \\
The length of PR in section decentralization, & \\
$S_{\mathrm{PR}}(\mathrm{m})$ & \\
\hline
\end{tabular}

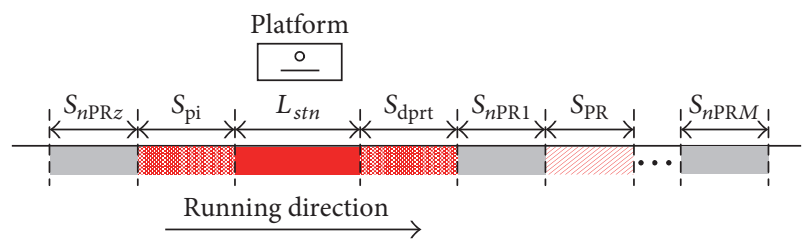

FIGURE 10: The sketch of the experimental line.

speed and the corresponding energy can be obtained from Figure 13. During the operation control strategy formulating, any ASA within these two points can be chosen to stop the train.

During the running, if a vehicle-borne battery related emergency happens, based on our proposed operation control strategy, the train can run for a given distance at the constant speed and then the emergency braking is performed to stop the train quickly to consume the battery energy as little as possible. From Figure 14, it can be seen that the train consumes less vehicle-borne battery energy and total running time is shorter at a higher initial speed. In our simulation, the initial speed is supposed to be $400 \mathrm{~km} / \mathrm{h}$ and the distance from the train location to the stop-point is $2774.5 \mathrm{~m}$ according to Table 8 . From (1)-(8) and (13), the distance for emergency braking with initial speed $400 \mathrm{~km} / \mathrm{h}$ is $2651.3 \mathrm{~m}$, leaving $123.2 \mathrm{~m}$ for the train running with constant 

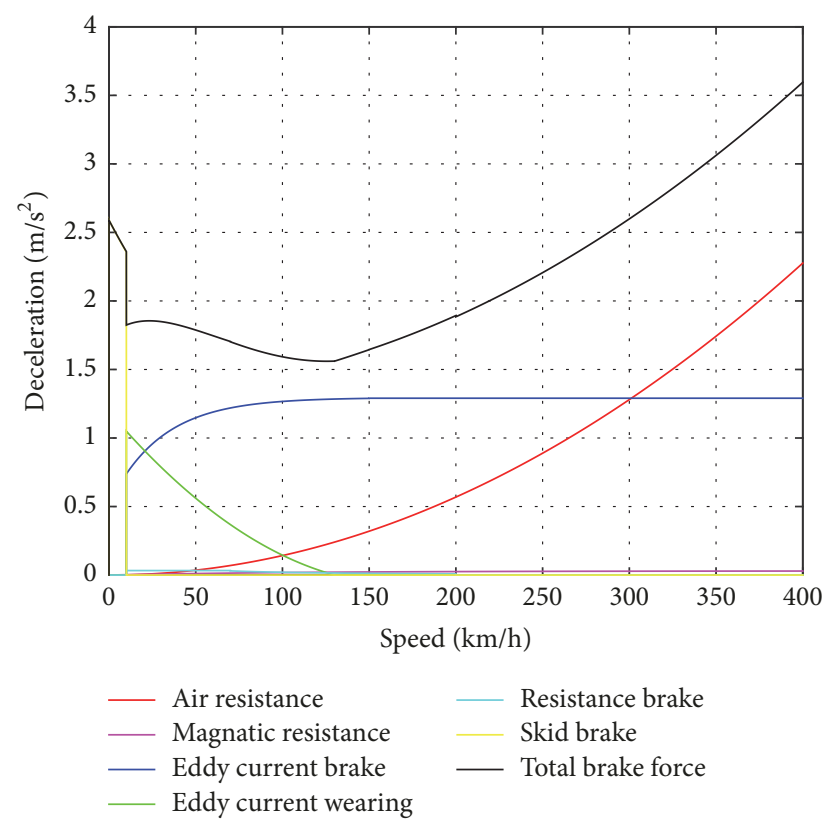

FIGURE 11: Deceleration of train at different speeds.

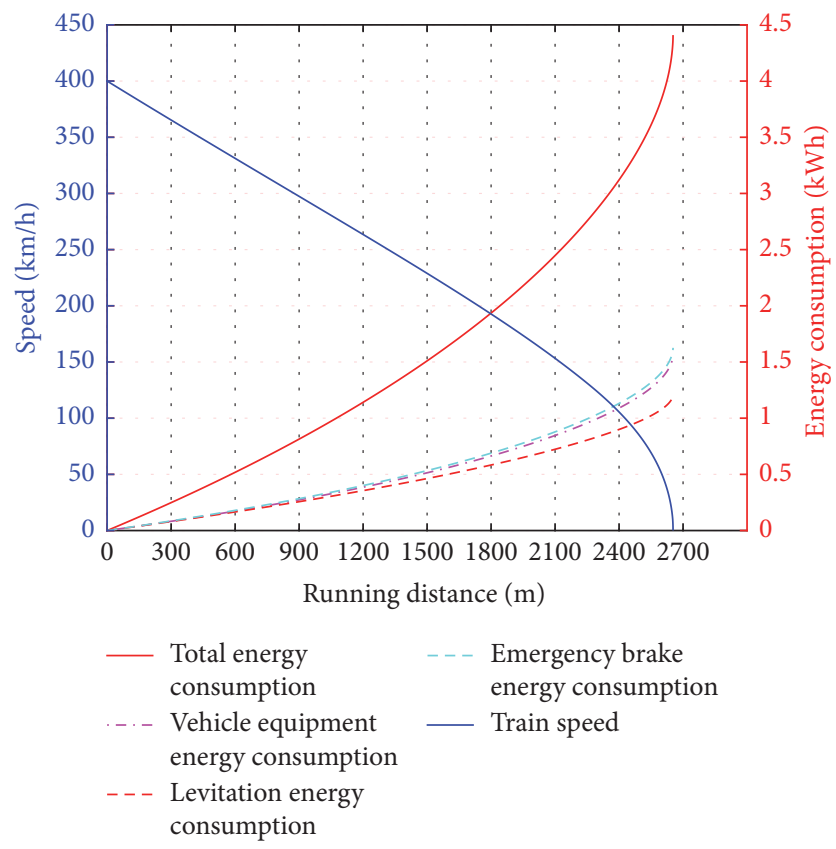

Figure 12: Speed-distance and energy-distance curves of the train under emergency braking.

speed at $400 \mathrm{~km} / \mathrm{h}$ and the total running time is $54.8 \mathrm{~s}$. From (11) and (12), the total energy consumption is $4.47 \mathrm{kWh}$.

As is shown in Figure 15, during the following operation for the connected trains, if the leading train performs an emergency or decelerates for some reasons, the following train should adjust the operation strategy to prevent it from crashing. Suppose the distance between the two trains is $15 \mathrm{~km}$. Because the minimum braking distance for the initial speed $400 \mathrm{~km} / \mathrm{h}$ is $2.65 \mathrm{~km}$ and the minimum capacity of

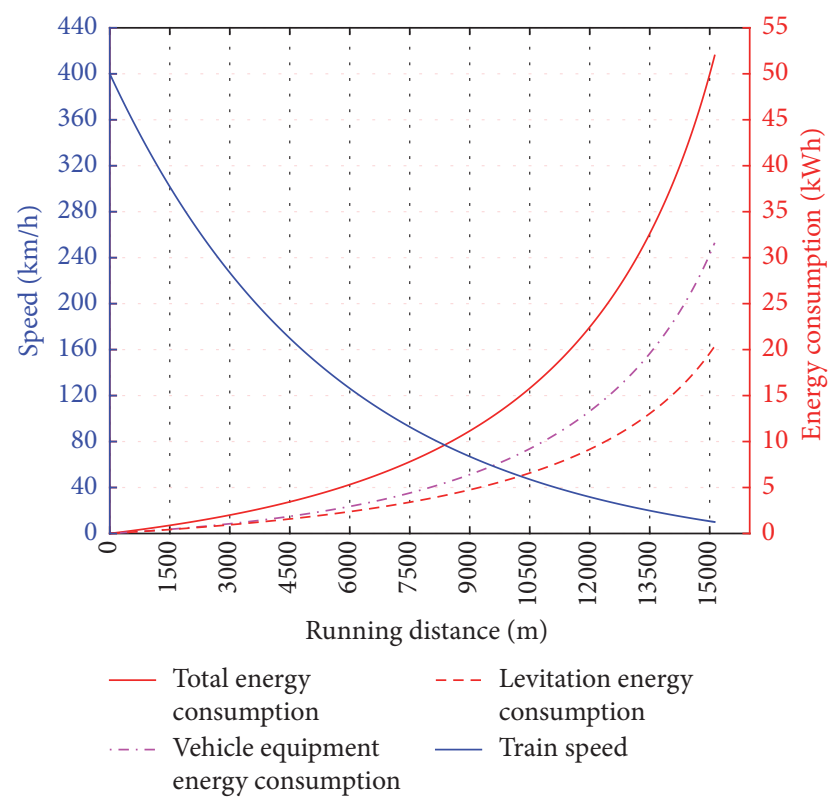

Figure 13: Speed-distance and energy-distance of a train under intrinsic resistance.

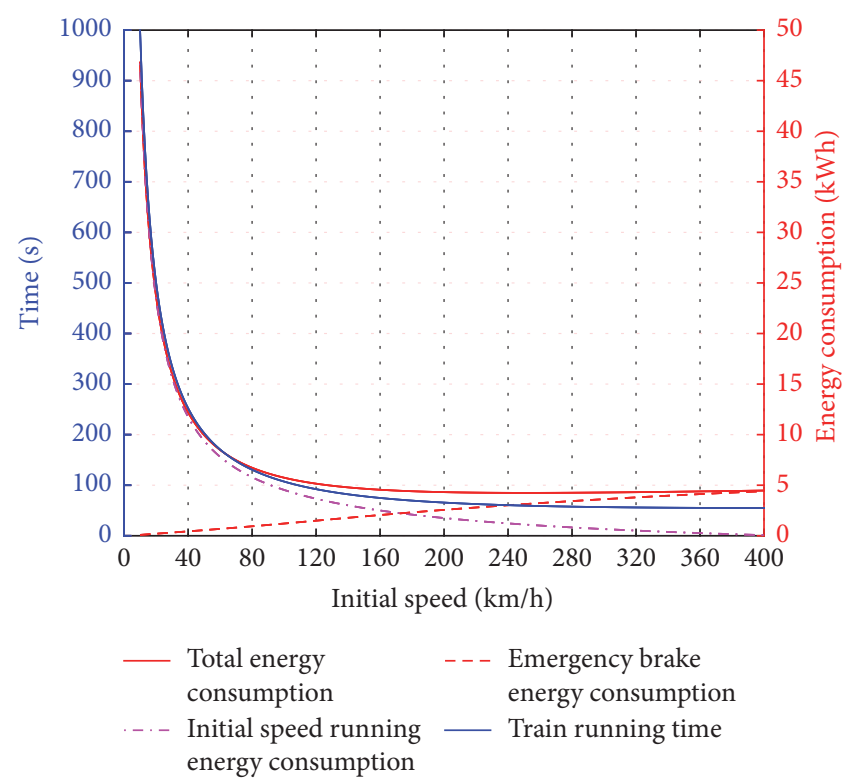

FIGURE 14: The running time and the energy consumption versus the initial speed.

the train-borne battery is $4.38 \mathrm{kWh}$, the operation control strategy for the following train is to speed up to $400 \mathrm{~km} / \mathrm{h}$, run for about $9.45 \mathrm{~km}$, and then perform a maximum braking to run to an ASA that is behind the leading train for about $3 \mathrm{~km}$ (here considering the safety margin of about $3 \mathrm{~km}$ ). Thus, the safety of the following operation for the connected trains can be guaranteed.

For the connected trains, in case of shutting-off PPS for the following train, the operation control strategy for the following train is to evaluate whether the following interval 


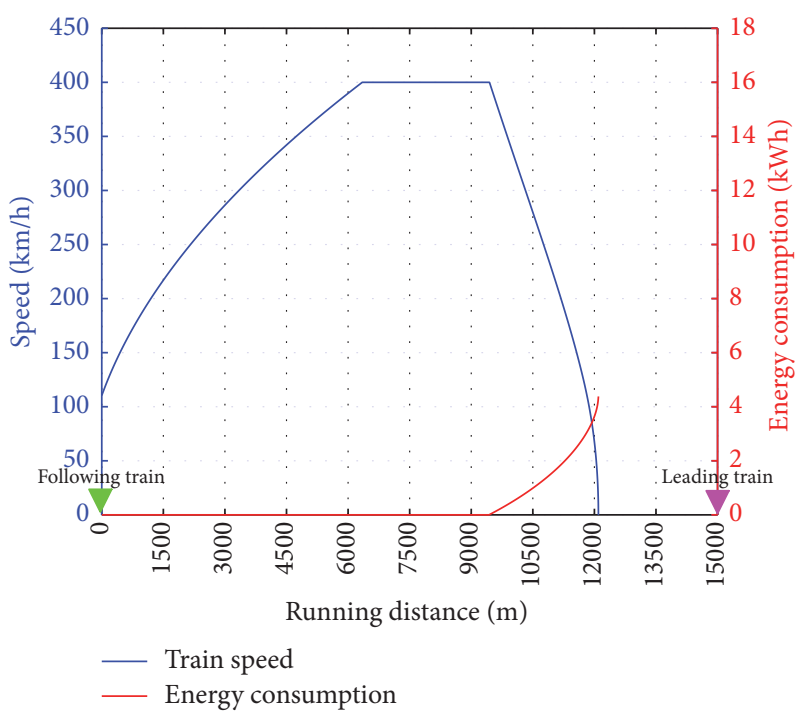

FIGURE 15: The following operation of the connected trains.

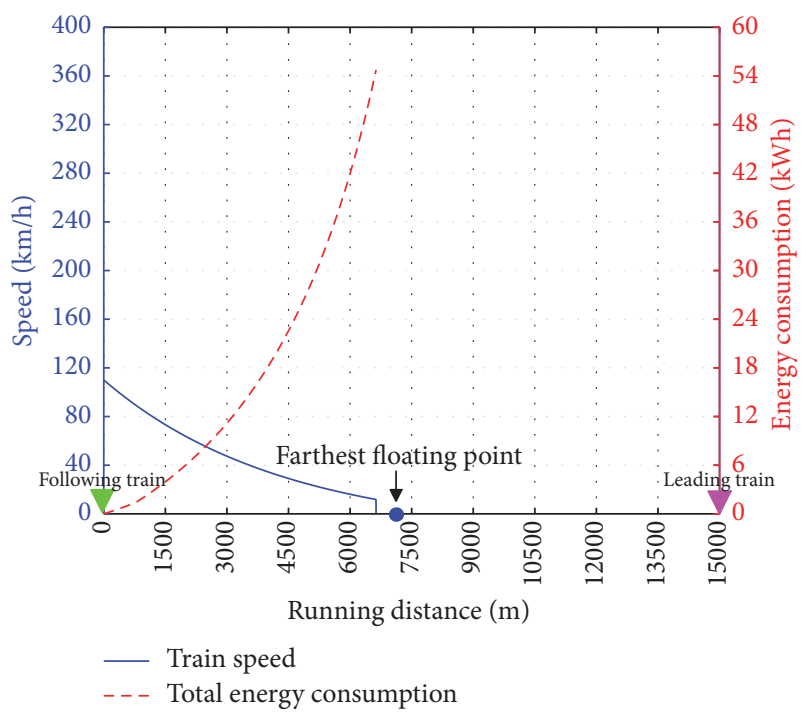

FIGURE 16: The floating running for the following train without PPS.

between the two trains is larger than the floating distance and the train-borne battery capacity is enough to supply the levitation for the floating. If true, the following train can float to the next ASA. As is shown in Figure 16, the energy for floating running of the following train is about $54 \mathrm{kWh}$, and the floating distance is about $6.6 \mathrm{~km}$. Because the following interval is larger than the floating distance, the following train can float to the ASA between the train location and the farthest floating point.

\section{Conclusions}

In this paper, considering the vehicle-borne battery condition monitoring, an operation control strategy is proposed to guarantee the operation safety of the connected maglev trains. The condition information of the vehicle-borne battery temperature and remaining capacity is gathered by IoT and collected by OCS via TCN; the connected trains share the condition data through RCS. The following train formulates the operation control strategy in real-time according to trainborne battery conditions and the operation state of the leading train. The simulation and experiment are given to demonstrate the effectiveness of the proposed strategy.

Further investigations could be concerned with operation control strategy formulation for the connected trains considering the state of other vehicle-borne equipment and combining these constraints together.

\section{Conflicts of Interest}

The authors declare that there are no conflicts of interest regarding the publication of this paper.

\section{Acknowledgments}

This work was supported in part by the Fundamental Research Funds for the Central Universities under Grant 2017JBM017, in part by National Key R\&D Program of China under Grant 2016YFB1200601, in part by National Natural Science Foundation of China under Grant 61573504, and in part by National Aerospace Science Foundation of China under Grant 201501M5001.

\section{References}

[1] L. Yan, "The linear motor powered transportation development and application in China," in Proceedings of the IEEE, vol. 97, pp. 1872-1880, 2009.

[2] L. G. Yan, "Development and application of the Maglev transportation system," IEEE Transactions on Applied Superconductivity, vol. 18, no. 2, pp. 92-99, 2008.

[3] H.-W. Lee, K.-C. Kim, and J. Lee, "Review of Maglev train technologies," IEEE Transactions on Magnetics, vol. 42, no. 7, pp. 1917-1925, 2006.

[4] J. Liu and W. Wu, "Research on 2-D speed protection curve and its algorithm of high-speed maglev transportation," China Railway Science, vol. 23, no. 4, pp. 106-110, 2002.

[5] D. Chen, J. Yin, L. Chen, and H. Xu, "Parallel control and management for high-speed maglev systems," IEEE Transactions on Intelligent Transportation Systems, vol. 18, no. 2, pp. 431-440, 2017.

[6] L. Liao and F. Köttig, "Review of hybrid prognostics approaches for remaining useful life prediction of engineered systems, and an application to battery life prediction," IEEE Transactions on Reliability, vol. 63, no. 1, pp. 191-207, 2014.

[7] M. Pilar, G. Miguel, S. Carlos et al., "On condition maintenance based on the impedance measurement for traction batteries: development and industrial implementation," IEEE Transactions on Industrial Electronics, vol. 60, no. 7, pp. 2750-2759, 2013.

[8] S. Dey, S. Mohon, P. Pisu, and B. Ayalew, "Sensor fault detection, isolation, and estimation in lithium-ion batteries," IEEE Transactions on Control Systems Technology, vol. 24, no. 6, pp. 2141-2149, 2016.

[9] P. Yang, N. Zhang, S. Zhang, K. Yang, L. Yu, and X. Shen, "Identifying the most valuable workers in fog-assisted spatial 
crowdsourcing," IEEE Internet of Things Journal, vol. 4, no. 5, pp. 1193-1203, 2017.

[10] Y. Kawamoto, N. Yamada, H. Nishiyama, N. Kato, Y. Shimizu, and Y. Zheng, "A Feedback Control Based Crowd Dynamics Management in IoT System," IEEE Internet of Things Journal, vol. 4, 1466, no. 5, p. 1476, 2017.

[11] Z. Long, X. Wang, and C. Fan, "Braking system multi-state analysis of maglev train based on Bayesian networks," in Proceedings of the 2017 Prognostics and System Health Management Conference (PHM-Harbin), pp. 1-8, Harbin, China, July 2017.

[12] X. Jiang, W. Nai, A. Yilixiati, Y. Yu, S. Wang, and D. Dong, "A train positioning mechanism for medium-low speed maglev train based on parity check cross coding inductive loop wire," in Proceedings of the 2017 3rd IEEE International Conference on Control Science and Systems Engineering (ICCSSE), pp. 269-272, Beijing, China, August 2017.

[13] A. J. Stankovic, "Research directions for the internet of things," IEEE Internet of Things Journal, vol. 1, no. 1, pp. 3-9, 2014.

[14] K. Zhang, J. Ni, K. Yang, X. Liang, J. Ren, and X. S. Shen, "Security and privacy in smart city applications: challenges and solutions," IEEE Communications Magazine, vol. 55, no. 1, pp. 122-129, 2017.

[15] J. Jiménez, J. L. Martín, A. Zuloaga, U. Bidarte, and J. Arias, "Comparison of two designs for the multifunction vehicle bus," IEEE Transactions on Computer-Aided Design of Integrated Circuits and Systems, vol. 25, no. 5, pp. 797-805, 2006.

[16] A. Chavarría, J. L. De Arroyabe, A. Zuloaga, J. Jimenez, J. L. Martin, and G. Aranguren, "Slave node architecture for train communications networks," pp. 2431-2436.

[17] G. A. zur Bonsen, "Multifunction vehicle bus (MVB)," in Proceedings of the 1995 IEEE International Workshop on Factory Communication Systems, WFCS'95, pp. 27-34, October 1995.

[18] Z. Liu, Y. Hou, and W. Fu, "Communication simulation of onboard diagnosis network in high-speed Maglev trains," Journal of Modern Transportation, vol. 19, no. 4, pp. 240-246, 2011.

[19] H. Kirrmann and P. A. Zuber, "The IEC/IEEE train communication network," IEEE Micro, vol. 21, no. 2, pp. 81-92, 2001.

[20] H. Zhang, Y. Xie, and Z. Long, "Fault detection based on tracking differentiator applied on the suspension system of maglev train," Mathematical Problems in Engineering, vol. 2015, Article ID 242431, 2015.

[21] B. Kim, H. Park, K. H. Kim, D. Godfrey, and K. Kim, "A Survey on Real-Time Communications in Wireless Sensor Networks," Wireless Communications and Mobile Computing, vol. 2017, pp. $1-14,2017$.

[22] Z. Long, X. Chen, and C. Fan, "Middle - Low speed maglev train suspension control system common cause failure risk analysis," in Proceedings of the 2017 36th Chinese Control Conference (CCC), pp. 7218-7224, Dalian, China, July 2017.

[23] H. He, R. Xiong, and H. Guo, "Online estimation of model parameters and state-of-charge of $\mathrm{LiFePO} 4$ batteries in electric vehicles," Applied Energy, vol. 89, no. 1, pp. 413-420, 2012.

[24] A. A. A. Elgammal and A. M. Sharaf, "Self-regulating particle swarm optimised controller for (photovoltaic-fuel cell) battery charging of hybrid electric vehicles," IET Electrical Systems in Transportation, vol. 2, no. 2, pp. 77-89, 2012.

[25] Z. Liu, Q. Ahmed, G. Rizzoni, and H. He, "Fault detection and isolation for lithium-ion battery system using structural analysis and sequential residual generation," in Proceedings of ASME 2014 Dynamic Systems and Control Conference, vol. 21, pp. 1-14, 2014.
[26] C. Hu, G. Jain, P. Tamirisa, and T. Gorka, "Method for estimating capacity and predicting remaining useful life of lithium-ion battery," Applied Energy, vol. 126, pp. 182-189, 2014. 


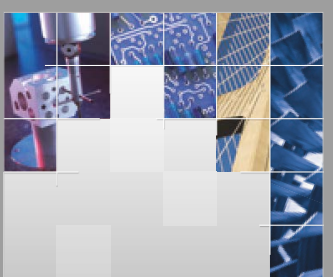

\section{Enfincering}
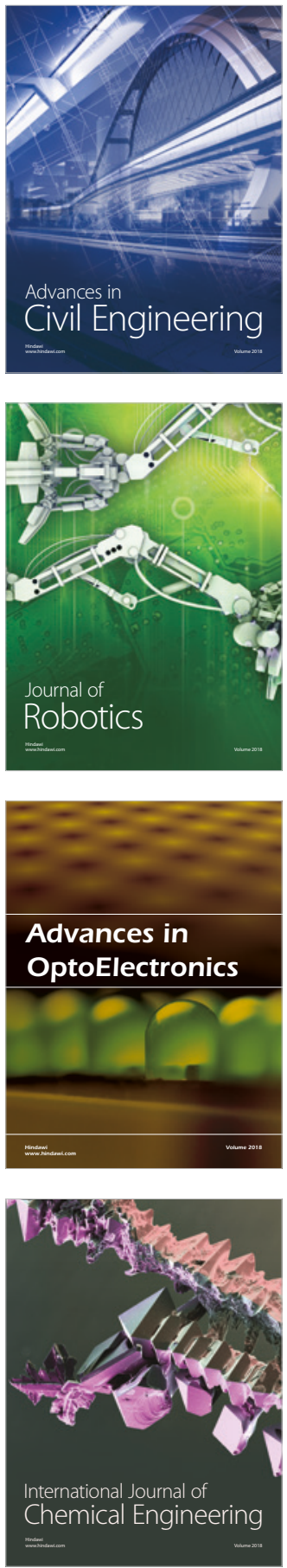

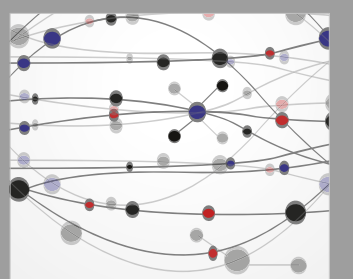

\section{Rotating \\ Machinery}

The Scientific World Journal

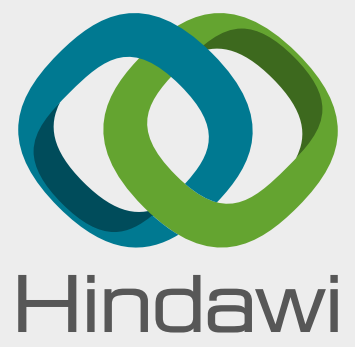

Submit your manuscripts at

www.hindawi.com
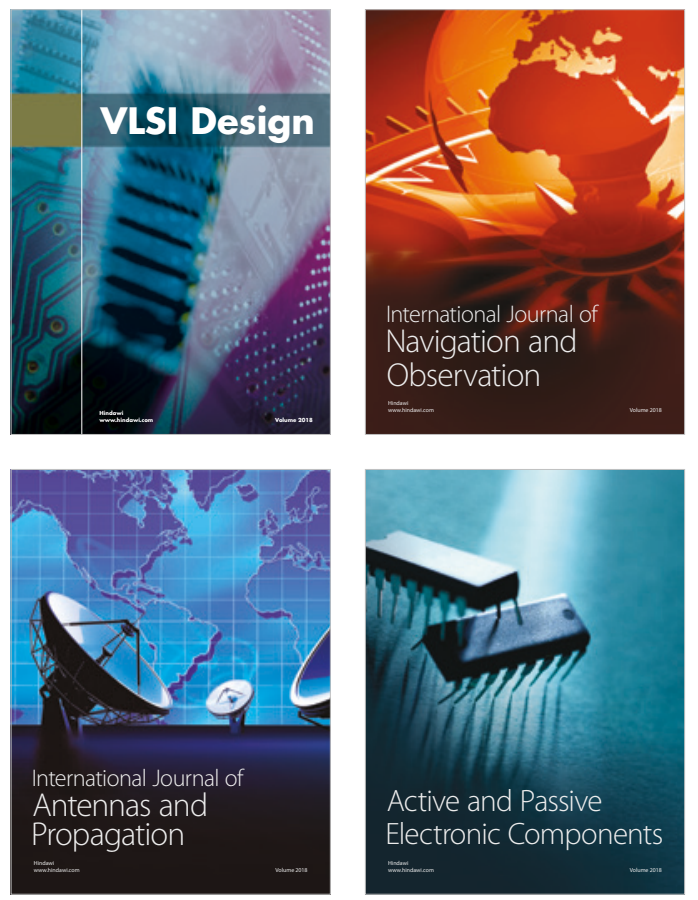
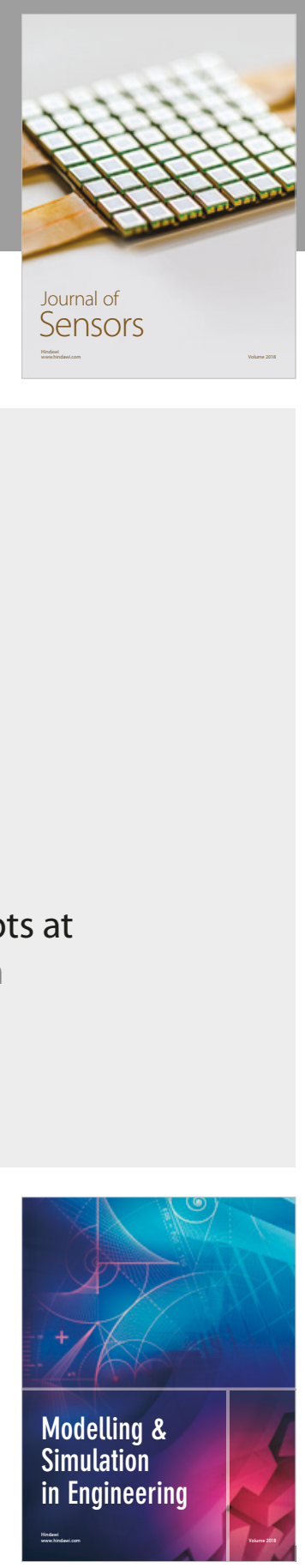

\section{Advances \\ Multimedia}
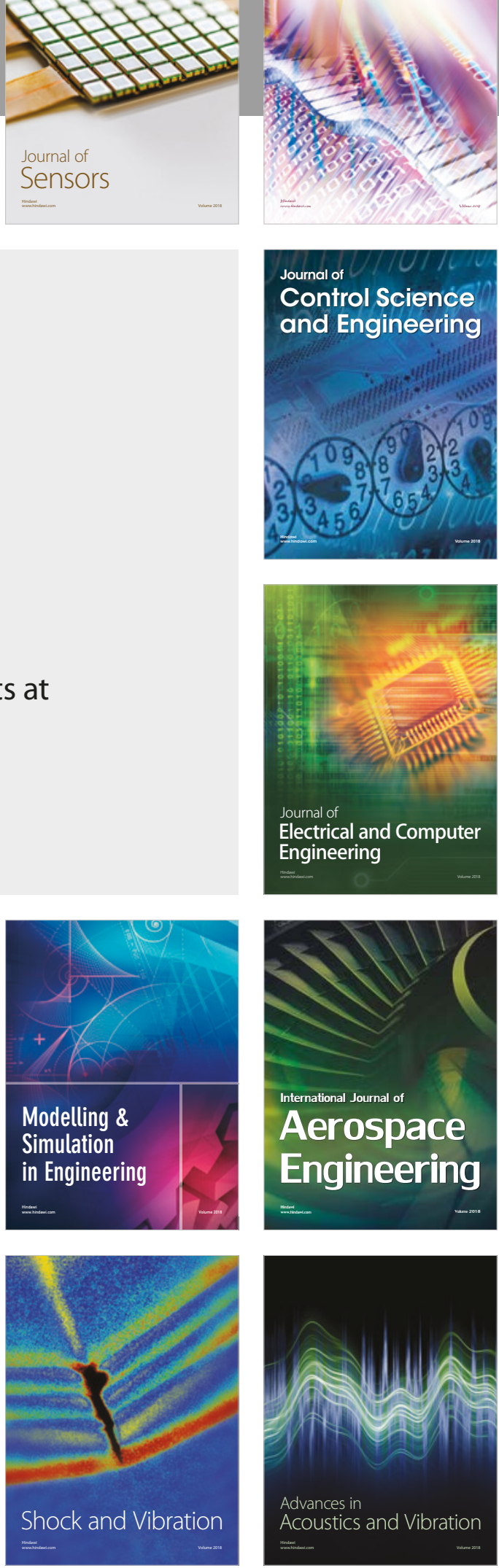